\title{
Immortalized Muscle Cell Model to Test the Exon Skipping Efficacy for Duchenne Muscular Dystrophy
}

\author{
Quynh Nguyen ${ }^{1}$ and Toshifumi Yokota ${ }^{1,2, *}$ \\ 1 Department of Medical Genetics, Faculty of Medicine and Dentistry, University of Alberta, 8812-112 St., \\ Edmonton, AB T6G 2H7, Canada; nguyenth@ualberta.ca \\ 2 The Friends of Garret Cumming Research and Muscular Dystrophy Canada HM Toupin Neurological \\ Science Research Chair, 8812-112 St., Edmonton, AB T6G 2H7, Canada \\ * Correspondence: toshifum@ualberta.ca; Tel.: +1-780-492-1102
}

Academic Editor: Stephen B. Liggett

Received: 22 September 2017; Accepted: 8 October 2017; Published: 16 October 2017

\begin{abstract}
Duchenne muscular dystrophy (DMD) is a lethal genetic disorder that most commonly results from mutations disrupting the reading frame of the dystrophin (DMD) gene. Among the therapeutic approaches employed, exon skipping using antisense oligonucleotides (AOs) is one of the most promising strategies. This strategy aims to restore the reading frame, thus producing a truncated, yet functioning dystrophin protein. In 2016, the Food and Drug Administration (FDA) conditionally approved the first AO-based drug, eteplirsen (Exondys 51), developed for DMD exon 51 skipping. An accurate and reproducible method to quantify exon skipping efficacy is essential for evaluating the therapeutic potential of different AOs sequences. However, previous in vitro screening studies have been hampered by the limited proliferative capacity and insufficient amounts of dystrophin expressed by primary muscle cell lines that have been the main system used to evaluate AOs sequences. In this paper, we illustrate the challenges associated with primary muscle cell lines and describe a novel approach that utilizes immortalized cell lines to quantitatively evaluate the exon skipping efficacy in in vitro studies.
\end{abstract}

Keywords: Duchenne/Becker muscular dystrophy (DMD/BMD); antisense oligonucleotide-mediated exon skipping therapy; hDMD mice; human telomerase reverse transcriptase (hTERT); cyclin-dependentkinase 4 (Cdk4); phosphorodiamidate morpholino oligomers (PMOs or morpholinos); C2C12; dystrophin-glycoprotein complex (DGC); golodirsen (SRP-4053); NS-065/NCNP-01

\section{Introduction}

Duchenne muscular dystrophy (DMD) is an X-linked recessive disorder affecting 1 in 3500-5000 live male births [1]. DMD is caused by mutations in dystrophin (DMD) gene located on the short arm of $\mathrm{X}$ chromosome (Xp21.3-p21.2) [2,3]. DMD is one of the largest genes in humans with 79 exons and an approximately $14 \mathrm{~kb}$ transcript constituting nearly $1 \%$ of the entire $\mathrm{X}$ chromosome [3]. DMD is caused by a variety of mutations such as deletions, duplications, small insertions/deletions (indels), and point mutations [4]. The mutation spectrum is predominated by deletions of one or more exons leading to the production of an out of frame protein resulting in an absence or insufficient amount of dystrophin and a classical manifestation of DMD. Some in-frame or truncating mutations that produce a partly functional protein lead to a milder form known as Becker muscular dystrophy (BMD) [5-7].

The dystrophin protein is expressed in skeletal, cardiac, smooth muscles and the central nervous system. Dystrophin has four domains: an actin-binding $\mathrm{N}$-terminal domain, a rod domain consisting of 24 spectrin-like repeat motifs, a cysteine-rich domain, and a C-terminal domain. Dystrophin is localized to the muscle fiber plasma membrane in association with dystrophin-glycoprotein complex (DGC). The DGC anchors the sarcolemma to the outermost myofilament layer of myofiber, 
providing membrane stabilization during muscle contraction [8,9]. The complex has also been shown to function in transduction of extracellular signals to the cell's cytoplasm [10,11].

In the absence of dystrophin, muscle fibers experience increased mechanical stress during contraction and relaxation cycles, with the sarcolemma membrane becoming fragile and susceptible to tearing and fragmentation [12]. This manifests as progressive muscle wasting and degeneration in DMD patients [13]. Additionally, this membrane instability increases intracellular calcium concentrations, thereby inducing calcium-dependent proteases and pro-inflammatory chemokines and cytokines leading to a secondary muscle degeneration and necrosis [14,15]. DMD remains largely asymptomatic for the first two years of life although affected children may show signs of delayed standing and walking. At age 3-5, clinical symptoms begin to manifest as walking abnormalities and elevated creatine kinase levels followed by generalized muscle atrophy and weakness [16-18]. As the disease progresses, respiratory and cardiac muscle deterioration will eventually lead to a death $[2,19,20]$.

\section{Exon Skipping Therapy for DMD}

An active body of research continues to explore therapeutic treatments to lessen the severity of DMD [21]. Currently, one of the most promising approaches is to employ antisense oligonucleotides (AOs) to induce exon skipping [22,23] (Figure 1). AOs are synthetic nucleic acid sequences that selectively bind to complementary target mRNA sequences. AOs can thereby interfere with the ribosomal complex, disrupt the splicing machinery or activate RNase H1 mediated degradation of AOs-mRNA heteroduplexes [24]. AO-mediated exon skipping can correct the reading frame by removing the mutated exon and/or its flanking exon(s) from the DMD pre-mRNA, leading to a truncated but partly functional dystrophin protein, thus producing a milder phenotype as in the case of BMD patients [25]. In animal and cell models of DMD, exon skipping has been demonstrated to correct deletion, duplication, nonsense, and splice site mutations [26-29]. An antisense phosphorodiamidate morpholino oligomer (PMO) targeting exon 51, called eteplirsen or Exondys 51 (Sarepta Therapeutics, Cambridge, MA, USA), was conditionally approved by the Food and Drug Administration (FDA) in 2016, and several PMOs targeting other DMD exons, including golodirsen (SRP-4053) and NS-065/NCNP-01 (NS Pharma, Paramus, NJ, USA) are currently under clinical trials. The exon skipping efficacy of different $\mathrm{AO}$ oligonucleotide sequences needs evaluation in vitro and in vivo. Animal models such as mice and dogs have been developed for DMD, however, each presents with its own limitations [30,31]. Naturally arising mutations in animal models that mimic human diseases are rare, and while transgenic mouse models expressing a human copy of the gene of interest have been developed, this gene expression profile remains within the context of the animal host [32-34]. As an example, the $m d x$ mouse model for DMD exhibits a milder phenotype: their lifespan is only reduced by $\sim 25 \%$ in contrast to humans where the disease is invariably fatal with $\sim 75 \%$ reduction in lifespan [31]. In addition, current animal models cannot recapitulate the wide range of mutations as found in human DMD patients. For the above reasons, primary human cell cultures derived from patients' muscle biopsies have been the pertinent tool to study the efficacy of potential therapeutic treatments prior to validation in in vivo systems. [35]. A cellular model is also less expensive and easier to set up and maintain as compared to an animal model. 


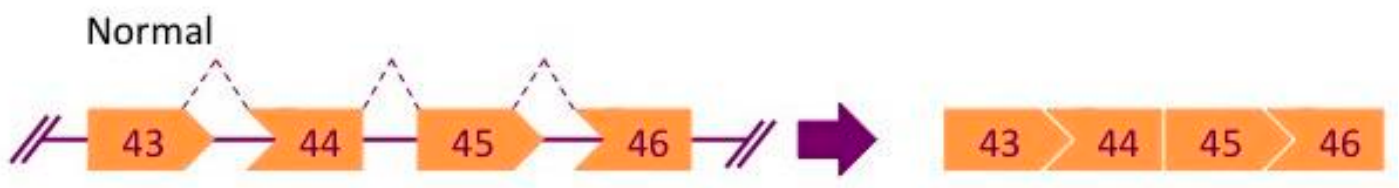

Exon 45 Deletion


Exon 44 Skipped

OUT-OF-FRAME
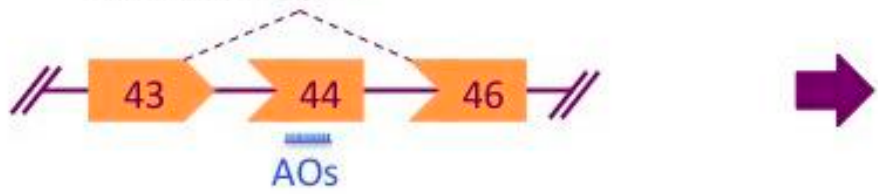

\section{$43>46$}

IN-FRAME

Figure 1. Mechanism of exon skipping therapy for Duchenne muscular dystrophy (DMD). Deletion of exon 45 results in a frameshift in the spliced mRNA. Treatment with AOs can correct the reading frame producing a truncated yet partly functional protein, as in the case of Becker muscular dystrophy (BMD).

\section{Challenges with Primary Cell Models for In Vitro Studies}

Primary DMD muscle cells are the most common cell type used in AO screening experiments [36]. Similar to other somatic cell lines, primary muscle cells have a limited proliferative capacity. After a certain number of cell divisions, the cells reach senescence for two primary reasons: the activation of p16-mediated cellular stress pathway, and the shortening of telomeres after each round of cell division triggering the p53 cascade and cellular apoptosis $[37,38]$. This limits the use of this model for repeated experiments in vitro. The proliferative lifespan is even shorter in cells derived from DMD patients due to the increased mitotic division that attempts to regenerate degenerating myofibers in vivo prior to biopsy isolations [39]. The timing of the muscle biopsy isolations can, therefore, introduce variations into the study. For repeated experiments, many isolations of primary cells are required which may result in problems with data reproducibility due to the heterogeneity associated with each biopsy procedure [40].

Prolonged in vitro cultivation may lead to deviations from normal biological processes that are important for cellular differentiation in a normal in vivo environment. One problem associated with primary muscle cell cultures is the decrease in myogenicity, and subsequently enrichment for non-myogenic cells with successive passaging. S. Perie et al. showed the percentage of desmin-positive cells (a marker specific for myogenic cells) decreased significantly during primary cell cultures' proliferative lifespan [41]. Although the study was done on cells derived from oculopharyngeal muscular dystrophy patients, it is reasonable to expect a similar decline in the case of other muscular dystrophies.

Quantification of dystrophin expression level is the criterion by which the effectiveness of in vitro exon skipping is evaluated. Primary muscle cells prove to be challenging in this regard as they may not express sufficient amount of dystrophin mRNA and protein for quantification. Previous studies have tried to overcome this limitation by using an extra cycle of PCR to quantify the first PCR cycle's products (nested PCR) [42-45]. However, this approach is likely to overestimate dystrophin levels, and the results are often not reproducible. Difficulties with accurate dystrophin quantification limit the potential to screen for more effective $\mathrm{AO}$ sequences for use in vitro, in vivo studies, and ultimately clinical trials. Since the cell type used for in vitro studies of dystrophin exon skipping efficacy could significantly affect the result, finding the appropriate system within which to test AOs has proved an active area of research. 
Previous studies have constructed cell models in which a plasmid harboring the native human dystrophin sequences was introduced [46]. This artificial screening cell model is easier to maintain than primary cells due to their higher proliferative capacity. However, due to the large size of human DMD gene's introns, it was not possible to incorporate the entire gene into a plasmid. Only selected exons were introduced into a plasmid, and some introns were replaced in these models, therefore, the efficacy of exon skipping might not reflect the in vivo efficacy. Additionally, protein expression cannot be measured in these models. Alternatively, to overcome insufficient mRNA and protein expression in primary cell lines, MyoD-transduced fibroblasts have been employed in exon skipping assays [47]. Dystrophin could be detected seven days after differentiation in dog cells, but required two weeks or more in human cells. MyoD-transduced fibroblasts also showed significantly higher dystrophin expression, and the results were reproducible. While MyoD-transduced fibroblasts were demonstrated to be a suitable model to study exon skipping efficacy, it required transduction by virus vectors, which is labor-intensive and time-consuming.

\section{Immortalized Cell Lines as a New Tool for In Vitro Studies}

To overcome problems with quantification, our group's recent studies have demonstrated the feasibility of quantifying dystrophin in immortalized DMD cell lines [33,48]. Muscle cells derived from DMD patients were transduced with human telomerase reverse transcriptase (hTERT) and cyclin-dependent-kinase 4 (CDK4)-expressing vectors to generate muscle stem cell lines with an enhanced proliferative capacity. hTERT is capable of elongating telomeres after each round of cell division while CDK-4 blocks the activation of p16-mediated cellular stress pathway that together lead to cell cycle senescence $[40,49]$. These immortalized cell lines have been previously tested to confirm that they maintained their myogenic signature and retained the ability to differentiate into myotubes [40]. Immortalization has also been shown to have no effect on other cellular processes [50].

In an effort to develop an in silico screening tool to predict the optimal target sites for exon skipping, our group utilized immortalized cell lines for subsequent in vitro testing to validate the predictive algorithm [48]. These cell lines had a high proliferative capacity and eight days after differentiation, sufficient mRNA and protein could be harvested to quantify expression levels of both by RT-PCR (non-nested) and Western blotting. To avoid overestimating the level of dystrophin, expression levels in treated DMD cells were calculated using a standard curve prepared from 1 to 10 percent protein of immortalized healthy skeletal muscle cells at nine days after differentiation as a positive control. The study found that novel AOs targeting exon 53 and exon 44 restored dystrophin expression to 5 and 12 percent of normal dystrophin expression levels in DMD muscle cells in vitro. We also observed a strong correlation of in vitro level of exon skipping and the predicted exon skipping efficacy calculated by our in silico screening tool, with an average $R^{2}$ of 0.89 for both exon 53 and 44 . Observed dystrophin protein level also correlated well with predicted values, at an average $R^{2}$ of 0.78 for exon 53 and 0.73 for exon 44 . Of the parameters tested, the binding energetics of the oligonucleotide to the RNA and the distance in bases of the target site from the splice acceptor site were confirmed to be the two most predictive.

In 2016, the FDA approved the first AO based drug, eteplirsen, designed for DMD exon 51 skipping. The FDA's approval of the drug remains a controversial decision; there is a dearth of evidence to support the effectiveness of eteplirsen in terms of its therapeutic effects in patients [51-54]. The FDA had previously rejected another candidate drug for DMD, 2'-O-methyl-phosphorothioate-based AO drisapersen, due to concerns over its therapeutic effectiveness and safety [55]. Previously, AO screenings relied heavily on RT-PCR from primary DMD muscle cell to evaluate dystrophin in-frame mRNA rescue level. As both drisapersen's and eteplirsen's exon 51 skipping efficacy was evaluated using this method, a more accurate methodology can, therefore, be used to identify even better target sequences [36,42]. Using our in silico screening tool to design AOs targeting DMD exon 51, and employing immortalized DMD muscle cell lines to quantitatively evaluate the exon skipping efficacy in vitro, we were able to find two new AOs sequences that induced exon skipping and rescued 
dystrophin expression with 12- and 7-fold greater efficiency than eteplirsen $[33,48,56]$. In this study, immortalized cell lines were generated from muscle cells of three healthy subjects and two DMD patients bearing deletions of exon 52 and exons 48-50. All healthy cell lines produced detectable levels of dystrophin three days after differentiation. A positive control from a healthy subject with the highest level of dystrophin was used to avoid overestimation of dystrophin expression. RT-PCR results using these cell lines found five novel sequences that showed significantly higher exon skipping efficacy compared to sequences identical to either eteplirsen (analog eteplirsen) or drisapersen (analog dirsapersen). In particular, treatment with a 30-mer AO targeting the beginning of exon 51 (called Ac0) had the highest proportion of in-frame transcripts at $72 \%$ of total dystrophin transcripts, 4 and 25 times higher than analog eteplirsen and drisapersen, respectively. Ac0-treated cells also had the highest level of dystrophin expression at $16 \%$ of wild-type followed by Ac48-treated cells at $13 \%$ as quantitated by Western blotting. Additionally, treatment with Ac0 or Ac48 showed more dystrophin positive myotubes than either analog eteplirsen or drisapersen in immunocytochemistry assays. The results were confirmed in primary muscle cell lines and in vivo in transgenic mice harboring the human $D M D$ gene (hDMD mice). Exon skipping efficacy was analyzed by RT-PCR in tibialis anterior muscles two weeks after intramuscular injection of Ac0 or analog eteplirsen. Ac0 induced over $7 \%$ exon skipping, compared to less than $5 \%$ in analog eteplirsen injected mice. These experiments also demonstrated for the first time that the observed exon skipping efficacy correlated well with the amount of dystrophin rescued. Therefore, we demonstrate that immortalized cell lines have the potential to be a powerful screening tool for identifying new sequences yielding higher exon skipping efficacy, and one that overcomes many of the challenges presented by dystrophin quantifications.

\section{Considerations Regarding Immortalized Cell Lines}

Several groups, including our own, have shown immortalized cell lines to be an invaluable tool to study cellular and molecular mechanisms in a disease model $[33,40,48,57]$. Thorough evaluations are nevertheless required to confirm the lines' stability and ability to retain the characteristics of the unmodified parental population. Since immortalization involves the introduction of exogenous DNA into the cells and overexpression of one or more cellular components, this may significantly change a culture's characteristics. The previously described hTERT, for example, has been reported to possess putative non-telomeric activities; evidence points to its interference with the Wnt pathway in mice essential for cellular differentiation [58-62]. The second target, CDK4, possesses key roles in the regulation of the cell cycle and other fundamental cellular processes. It is therefore essential to determine if genetic modifications related to CDK4 have secondary effects that could affect the validity of these models. Another consideration is that immortalized cell lines, unlike primary cell lines, are likely to be maintained for prolonged periods in tissue culture conditions. Time in tissue culture has been associated with loss of myogenic potential, thus further emphasizing the necessity of validating immortalized cell lines' divergence from their primary parental population [41]. Phenotype drifts have been observed in other immortalized cell lines such as in the case of $\mathrm{C} 2 \mathrm{C} 12$ cells, a phenomenon that could result in data reproducibility problems [40].

Although in vitro models remain an approximation of the level of complexity of a disease in a human body, immortalized cell lines prove to be a powerful tool for therapeutic preclinical studies.

Acknowledgments: We thank Vincent Mouly (University of Paris 6; Pierre-and-Marie-Curie University) for preparing immortalized muscle cells. This work was supported by the University of Alberta Faculty of Medicine and Dentistry, Parent Project Muscular Dystrophy USA, the Canadian Institutes of Health Research (FRN134134 and 132574), the Friends of Garrett Cumming Research Funds, HM Toupin Neurological Science Research Funds, Muscular Dystrophy Canada, the Canada Foundation for Innovation (30819), Alberta Enterprise and Advanced Education, the Women and Children's Health Research Institute, Alberta Innovates-Health Solutions, and the Japan Society for the Promotion of Science.

Conflicts of Interest: The authors declare no conflict of interest. 


\section{References}

1. Emery, A.E.H. Population frequencies of inherited neuromuscular diseases-A world survey. Neuromuscul. Disord. 1991, 1, 19-29. [CrossRef]

2. Hoffman, E.P.; Brown, R.H.; Kunkel, L.M. Dystrophin: The protein product of the duchenne muscular dystrophy locus. Cell 1987, 51, 919-928. [CrossRef]

3. Koenig, M.; Hoffman, E.P.; Bertelson, C.J.; Monaco, A.P.; Feener, C.; Kunkel, L.M. Complete cloning of the duchenne muscular dystrophy (DMD) cDNA and preliminary genomic organization of the DMD gene in normal and affected individuals. Cell 1987, 50, 509-517. [CrossRef]

4. Yokota, T.; Pistilli, E.; Duddy, W.; Nagaraju, K. Potential of oligonucleotide-mediated exon-skipping therapy for Duchenne muscular dystrophy. Expert Opin. Biol. Ther. 2007, 7, 831-842. [CrossRef] [PubMed]

5. Hoffman, E.P.; Kunkel, L.M.; Angelini, C.; Clarke, A.; Johnson, M.; Harris, J.B. Improved diagnosis of Becker muscular dystrophy by dystrophin testing. Neurology 1989, 39, 1011-1017. [CrossRef] [PubMed]

6. Arahata, K.; Hoffman, E.P.; Kunkel, L.M.; Ishiura, S.; Tsukahara, T.; Ishihara, T.; Sunohara, N.; Nonaka, I.; Ozawa, E.; Sugita, H. Dystrophin diagnosis: Comparison of dystrophin abnormalities by immunofluorescence and immunoblot analyses. Proc. Natl. Acad. Sci. USA 1989, 86, 7154-7158. [CrossRef] [PubMed]

7. Neri, M.; Torelli, S.; Brown, S.; Ugo, I.; Sabatelli, P.; Merlini, L.; Spitali, P.; Rimessi, P.; Gualandi, F.; Sewry, C.; et al. Dystrophin levels as low as 30\% are sufficient to avoid muscular dystrophy in the human. Neuromuscul. Disord. 2007, 17, 913-918. [CrossRef] [PubMed]

8. Campbell, K.P. Three muscular dystrophies: Loss of cytoskeleton-extracellular matrix linkage. Cell 1995, 80, 675-679. [CrossRef]

9. Whitmore, C.; Morgan, J. What do mouse models of muscular dystrophy tell us about the DAPC and its components? Int. J. Exp. Pathol. 2014, 95, 365-377. [CrossRef] [PubMed]

10. Sunada, Y.; Campbell, K.P. Dystrophin-glycoprotein complex: Molecular organization and critical roles in skeletal muscle. Curr. Opin. Neurol. 1995, 8, 379-384. [CrossRef] [PubMed]

11. Nichols, B.; Takeda, S.; Yokota, T. Nonmechanical Roles of Dystrophin and Associated Proteins in Exercise, Neuromuscular Junctions, and Brains. Brain Sci. 2015, 5, 275-298. [CrossRef] [PubMed]

12. Lapidos, K.A.; Kakkar, R.; McNally, E.M. The Dystrophin Glycoprotein Complex: Signaling Strength and Integrity for the Sarcolemma. Circ. Res. 2004, 94, 1023-1031. [CrossRef] [PubMed]

13. Nakamura, A.; Takeda, S. Mammalian models of duchenne muscular dystrophy: Pathological characteristics and therapeutic applications. J. Biomed. Biotechnol. 2011, 2011, 184393. [CrossRef] [PubMed]

14. Yeung, E.W.; Whitehead, N.P.; Suchyna, T.M.; Gottlieb, P.A.; Sachs, F.; Allen, D.G. Effects of stretch-activated channel blockers on $\left[\mathrm{Ca}^{2+}\right]_{\mathrm{i}}$ and muscle damage in the mdx mouse. J. Physiol. 2005, 562, 367-380. [CrossRef] [PubMed]

15. Porter, J.D. A chronic inflammatory response dominates the skeletal muscle molecular signature in dystrophin-deficient $m d x$ mice. Hum. Mol. Genet. 2002, 11, 263-272. [CrossRef] [PubMed]

16. Moser, H. Duchenne muscular dystrophy: Pathogenetic aspects and genetic prevention. Hum. Genet. 1984, 66, 17-40. [CrossRef] [PubMed]

17. Duchenne, G.-B.-A. The pathology of paralysis with muscular degeneration (Paralysie Myosclerotique), or paralysis with apparent hypertrophy. Br. Med. J. 1867, 2, 541-542. [CrossRef] [PubMed]

18. Hoffman, E.F.; Kunkel, L.M. Dystrophin Abnormalities in Duchenne/Becker Muscular Review Dystrophy genes. Cell 1989, 2, 1019-1029.

19. Eagle, M.; Baudouin, S.V.; Chandler, C.; Giddings, D.R.; Bullock, R.; Bushby, K. Survival in Duchenne muscular dystrophy: Improvements in life expectancy since 1967 and the impact of home nocturnal ventilation. Neuromuscul. Disord. 2002, 12, 926-929. [CrossRef]

20. Passamano, L.; Taglia, A.; Palladino, A.; Viggiano, E.; D’Ambrosio, P.; Scutifero, M.; Cecio, M.R.; Torre, V.; De Luca, F.; Picillo, E.; et al. Improvement of survival in Duchenne Muscular Dystrophy: Retrospective analysis of 835 patients. Acta Myol. 2012, 31, 121-125. [PubMed]

21. Pandey, S.N.; Kesari, A.; Yokota, T.; Pandey, G.S. Muscular dystrophy: Disease mechanisms and therapies. BioMed Res. Int. 2015, 2015, 456348. [CrossRef] [PubMed]

22. Touznik, A.; Lee, J.J.A.; Yokota, T. New developments in exon skipping and splice modulation therapies for neuromuscular diseases. Expert Opin. Biol. Ther. 2014, 14, 809-819. [CrossRef] [PubMed] 
23. Lee, J.; Yokota, T. Antisense Therapy in Neurology. J. Pers. Med. 2013, 3, 144-176. [CrossRef] [PubMed]

24. Kuzmiak, H.A.; Maquat, L.E. Applying nonsense-mediated mRNA decay research to the clinic: Progress and challenges. Trends Mol. Med. 2006, 12, 306-316. [CrossRef] [PubMed]

25. Lee, J.J.A.; Yokota, T. Translational Research in Nucleic Acid Therapies for Muscular Dystrophies. In Translational Research in Muscular Dystrophy; Springer: Tokyo, Japan, 2016; pp. 87-102.

26. Aoki, Y.; Nakamura, A.; Yokota, T.; Saito, T.; Okazawa, H.; Nagata, T.; Takeda, S. In-frame Dystrophin Following Exon 51-Skipping Improves Muscle Pathology and Function in the Exon 52-Deficient $m d x$ Mouse. Mol. Ther. 2010, 18, 1995-2005. [CrossRef] [PubMed]

27. Yokota, T.; Duddy, W.; Echigoya, Y.; Kolski, H. Exon skipping for nonsense mutations in Duchenne muscular dystrophy: Too many mutations, too few patients? Expert Opin. Biol. Ther. 2012, 12, 1141-1152. [CrossRef] [PubMed]

28. Maruyama, R.; Echigoya, Y.; Caluseriu, O.; Aoki, Y.; Takeda, S.; Yokota, T. Systemic delivery of morpholinos to skip multiple exons in a dog model of duchenne muscular dystrophy. In Methods in Molecular Biology; Moulton, H., Moulton, J., Eds.; Humana Press: New York, NY, USA, 2017; Volume 1565, pp. 201-213. ISBN 978-1-4939-6817-6.

29. Wein, N.; Vulin, A.; Findlay, A.R.; Gumienny, F.; Huang, N.; Wilton, S.D.; Flanigan, K.M. Efficient Skipping of Single Exon Duplications in DMD Patient-Derived Cell Lines Using an Antisense Oligonucleotide Approach. J. Neuromuscul. Dis. 2017, 4, 199-207. [CrossRef] [PubMed]

30. Rodrigues, M.; Echigoya, Y.; Fukada, S.-I.; Yokota, T. Current Translational Research and Murine Models For Duchenne Muscular Dystrophy. J. Neuromuscul. Dis. 2016, 3, 29-48. [CrossRef] [PubMed]

31. McGreevy, J.W.; Hakim, C.H.; McIntosh, M.A.; Duan, D. Animal models of Duchenne muscular dystrophy: From basic mechanisms to gene therapy. Dis. Model. Mech. 2015, 8, 195-213. [CrossRef] [PubMed]

32. Yu, X.; Bao, B.; Echigoya, Y.; Yokota, T. Dystrophin-deficient large animal models: Translational research and exon skipping. Am. J. Transl. Res. 2015, 7, 1314-1331. [PubMed]

33. Echigoya, Y.; Lim, K.R.Q.; Trieu, N.; Bao, B.; Miskew, B.; Vila, M.C.; Novak, J.S.; Hara, Y.; Lee, J.; Touznik, A.; et al. Quantitative antisense screening and optimization for exon 51 skipping in Duchenne muscular dystrophy. Mol. Ther. 2017, 25. [CrossRef] [PubMed]

34. Young, C.S.; Mokhonova, E.; Quinonez, M.; Pyle, A.D.; Spencer, M.J. Creation of a Novel Humanized Dystrophic Mouse Model of Duchenne Muscular Dystrophy and Application of a CRISPR/Cas9 Gene Editing Therapy. J. Neuromuscul. Dis. 2017, 4, 139-145. [CrossRef] [PubMed]

35. Aartsma-Rus, A.; Janson, A.A.M.; Kaman, W.E.; Bremmer-Bout, M.; den Dunnen, J.T.; Baas, F.; van Ommen, G.J.B.; van Deutekom, J.C.T. Therapeutic antisense-induced exon skipping in cultured muscle cells from six different DMD patients. Hum. Mol. Genet. 2003, 12, 907-914. [CrossRef] [PubMed]

36. Arechavala-Gomeza, V.; Graham, I.R.; Popplewell, L.J.; Adams, A.M.; Aartsma-Rus, A.; Kinali, M.; Morgan, J.E.; van Deutekom, J.C.; Wilton, S.D.; Dickson, G.; et al. Comparative analysis of antisense oligonucleotide sequences for targeted skipping of exon 51 during dystrophin pre-mRNA splicing in human muscle. Hum. Gene Ther. 2007, 18, 798-810. [CrossRef] [PubMed]

37. Renault, V.; Thorne, L.-E.; Eriksson, P.-O.; Butler-Browne, G.; Mouly, V. Regenerative potential of human skeletal muscle during aging. Aging Cell 2002, 1, 132-139. [CrossRef] [PubMed]

38. Wright, W.E.; Shay, J.W. Historical claims and current interpretations of replicative aging. Nat. Biotechnol. 2002, 20, 682-688. [CrossRef] [PubMed]

39. Webster, C.; Blau, H.M. Accelerated age-related decline in replicative life-span of Duchenne muscular dystrophy myoblasts: Implications for cell and gene therapy. Somat. Cell Mol. Genet. 1990, 16, 557-565. [CrossRef] [PubMed]

40. Mamchaoui, K.; Trollet, C.; Bigot, A.; Negroni, E.; Chaouch, S.; Wolff, A.; Kandalla, P.K.; Marie, S.; Di Santo, J.; St Guily, J.; et al. Immortalized pathological human myoblasts: Towards a universal tool for the study of neuromuscular disorders. Skelet. Muscle 2011, 1, 34. [CrossRef] [PubMed]

41. Périé, S.; Mamchaoui, K.; Mouly, V.; Blot, S.; Bouazza, B.; Thornell, L.E.; St Guily, J.L.; Butler-Browne, G. Premature proliferative arrest of cricopharyngeal myoblasts in oculo-pharyngeal muscular dystrophy: Therapeutic perspectives of autologous myoblast transplantation. Neuromuscul. Disord. 2006, 16, 770-781. [CrossRef] [PubMed] 
42. Aartsma-Rus, A.; Bremmer-Bout, M.; Janson, A.A.M.; Den Dunnen, J.T.; Van Ommen, G.J.B.; Van Deutekom, J.C.T. Targeted exon skipping as a potential gene correction therapy for Duchenne muscular dystrophy. Neuromuscul. Disord. 2002, 12, S71-S77. [CrossRef]

43. Aartsma-Rus, A.; De winter, C.L.; Janson, A.A.M.; Kaman, W.E.; Van ommen, G.B.; Den dunnen, J.T.; Van deutekom, J.C.T. Functional Analysis of 114 Exon-Internal AONs for Targeted DMD Exon Skipping: Indication for Steric Hindrance of SR Protein Binding Sites. Oligonucleotides 2005, 15, 284-297. [CrossRef] [PubMed]

44. Aartsma-Rus, A.; Janson, A.A.; van Ommen, G.-J.B.; van Deutekom, J.C. Antisense-induced exon skipping for duplications in Duchenne muscular dystrophy. BMC Med. Genet. 2007, 8, 43. [CrossRef] [PubMed]

45. Popplewell, L.J.; Adkin, C.; Arechavala-Gomeza, V.; Aartsma-Rus, A.; de Winter, C.L.; Wilton, S.D.; Morgan, J.E.; Muntoni, F.; Graham, I.R.; Dickson, G. Comparative analysis of antisense oligonucleotide sequences targeting exon 53 of the human DMD gene: Implications for future clinical trials. Neuromuscul. Disord. 2010, 20, 102-110. [CrossRef] [PubMed]

46. Shimo, T.; Tachibana, K.; Saito, K.; Yoshida, T.; Tomita, E.; Waki, R.; Yamamoto, T.; Doi, T.; Inoue, T.; Kawakami, J.; et al. Design and evaluation of locked nucleic acid-based splice-switching oligonucleotides in vitro. Nucleic Acids Res. 2014, 42, 8174-8187. [CrossRef] [PubMed]

47. Saito, T.; Nakamura, A.; Aoki, Y.; Yokota, T.; Okada, T.; Osawa, M.; Takeda, S. Antisense PMO found in Dystrophic Dog model was effective in cells from exon 7-deleted DMD patient. PLoS ONE 2010, 5, e12239. [CrossRef] [PubMed]

48. Echigoya, Y.; Mouly, V.; Garcia, L.; Yokota, T.; Duddy, W. In silico screening based on predictive algorithms as a design tool for exon skipping oligonucleotides in duchenne muscular dystrophy. PLoS ONE 2015, 10, e0120058. [CrossRef] [PubMed]

49. Zhu, C.H.; Mouly, V.; Cooper, R.N.; Mamchaoui, K.; Bigot, A.; Shay, J.W.; Di Santo, J.P.; Butler-Browne, G.S.; Wright, W.E. Cellular senescence in human myoblasts is overcome by human telomerase reverse transcriptase and cyclin-dependent kinase 4: Consequences in aging muscle and therapeutic strategies for muscular dystrophies. Aging Cell 2007, 6, 515-523. [CrossRef] [PubMed]

50. Thorley, M.; Duguez, S.; Mazza, E.M.C.; Valsoni, S.; Bigot, A.; Mamchaoui, K.; Harmon, B.; Voit, T.; Mouly, V.; Duddy, W. Skeletal muscle characteristics are preserved in hTERT/cdk4 human myogenic cell lines. Skelet. Muscle 2016, 6, 43. [CrossRef] [PubMed]

51. The Lancet. Patient need versus evidence: A balancing act. Lancet 2016, 388, 1350. [CrossRef]

52. Aartsma-Rus, A.; Krieg, A.M. FDA Approves Eteplirsen for Duchenne Muscular Dystrophy: The Next Chapter in the Eteplirsen Saga. Nucleic Acid Ther. 2017, 27, 1-3. [CrossRef] [PubMed]

53. Lim, K.R.Q.; Maruyama, R.; Yokota, T. Eteplirsen in the treatment of Duchenne muscular dystrophy. Drug Des. Dev. Ther. 2017, 11, 533-545. [CrossRef] [PubMed]

54. Kesselheim, A.S.; Avorn, J. Approving a Problematic Muscular Dystrophy Drug. JAMA 2016, 316, $2357-2358$. [CrossRef] [PubMed]

55. Voit, T.; Topaloglu, H.; Straub, V.; Muntoni, F.; Deconinck, N.; Campion, G.; De Kimpe, S.J.; Eagle, M.; Guglieri, M.; Hood, S.; et al. Safety and efficacy of drisapersen for the treatment of Duchenne muscular dystrophy (DEMAND II): An exploratory, randomised, placebo-controlled phase 2 study. Lancet Neurol. 2014, 13, 987-996. [CrossRef]

56. Guncay, A.; Yokota, T. Antisense oligonucleotide drugs for Duchenne muscular dystrophy: How far have we come and what does the future hold? Future Med. Chem. 2015, 7, 1631-1635. [CrossRef] [PubMed]

57. Chaouch, S.; Mouly, V.; Goyenvalle, A.; Vulin, A.; Mamchaoui, K.; Negroni, E.; Di Santo, J.; Butler-Browne, G.; Torrente, Y.; Garcia, L.; et al. Immortalized Skin Fibroblasts Expressing Conditional MyoD as a Renewable and Reliable Source of Converted Human Muscle Cells to Assess Therapeutic Strategies for Muscular Dystrophies: Validation of an Exon-Skipping Approach to Restore Dystrophin in Duchen. Hum. Gene Ther. 2009, 20, 784-790. [CrossRef] [PubMed]

58. González-Suárez, E.; Samper, E.; Ramírez, A.; Flores, J.M.; Martín-Caballero, J.; Jorcano, J.L.; Blasco, M.A. Increased epidermal tumors and increased skin wound healing in transgenic mice overexpressing the catalytic subunit of telomerase, mTERT, in basal keratinocytes. EMBO J. 2001, 20, 2619-2630. [CrossRef] [PubMed] 
59. Stewart, S.A.; Hahn, W.C.; O’Connor, B.F.; Banner, E.N.; Lundberg, A.S.; Modha, P.; Mizuno, H.; Brooks, M.W.; Fleming, M.; Zimonjic, D.B.; et al. Telomerase contributes to tumorigenesis by a telomere length-independent mechanism. Proc. Natl. Acad. Sci. USA 2002, 99, 12606-12611. [CrossRef] [PubMed]

60. Smith, L.L.; Coller, H.A.; Roberts, J.M. Telomerase modulates expression of growth-controlling genes and enhances cell proliferation. Nat. Cell Biol. 2003, 5, 474-479. [CrossRef] [PubMed]

61. Park, J.-I.; Venteicher, A.S.; Hong, J.Y.; Choi, J.; Jun, S.; Shkreli, M.; Chang, W.; Meng, Z.; Cheung, P.; Ji, H.; et al. Telomerase modulates Wnt signalling by association with target gene chromatin. Nature 2009, 460, 66-72. [CrossRef] [PubMed]

62. Tsivitse, S. Notch and Wnt signaling, physiological stimuli and postnatal myogenesis. Int. J. Biol. Sci. 2010, 6, 268-281. [CrossRef] [PubMed]

(C) 2017 by the authors. Licensee MDPI, Basel, Switzerland. This article is an open access article distributed under the terms and conditions of the Creative Commons Attribution (CC BY) license (http:/ / creativecommons.org/licenses/by/4.0/). 